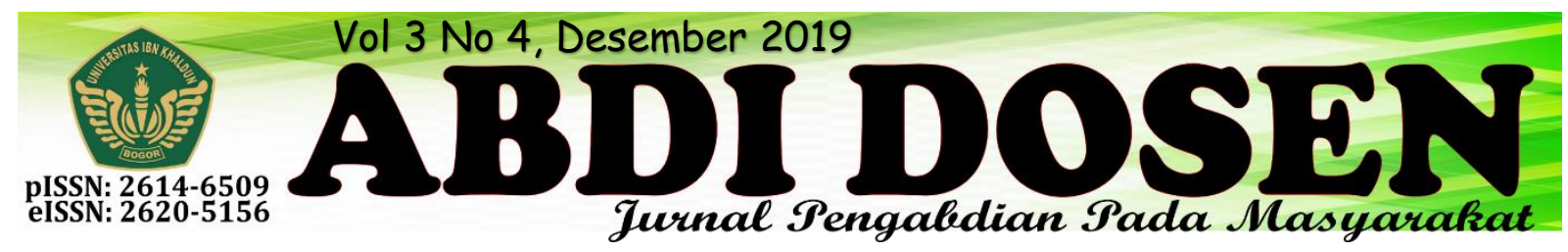

\title{
PENERAPAN DAN PENGEMBANGAN PROGRAM PEMBERDAYAAN MASYARAKAT BERBASIS PENDIDIKAN DI DESA GUNUNG MALANG
}

\author{
Asti Marlina ${ }^{1}$, M. Farid, Michael Yudhea ${ }^{2}$ \\ asti@uika-bogor.ac.id \\ Fakultas Ekonomi dan Bisnis Universitas Ibn Khaldun ${ }^{1}$, Mahasiswa KKN Kelompok 05 Tahun $2018^{2}$
}

\begin{abstract}
ABSTRAK
Pengabdian masyarakat adalah suatu kegiatan yang bertujuan membantu masyarakat tertentu dalam beberapa aktivitas tanpa mengharapkan imbalan dalam bentuk apapun. Dalam mengembangkan kesejahteraan dan kemajuan bangsa Indonesia Kegiatan Pengabdian Masyarakat merupakan salah satu bagian dari Tri Dharma Perguruan Tinggi. Salah satu desa yang memiliki potensi dalam pembangunan nilai sosial dan ekonomi adalah Desa Gunung malang Kecamatan Tenjolaya Kabupaten Bogor. Hal itu karena di desa ini merupakan salah satu desa dengan jumlah penduduk terbanyak di Kecamatan Tenjolaya dan memiliki banyak potensi muatan lokal yang variatif yang dapat menumbuhkan jiwa wirausaha dari tiap warga didesa gunung malang. Peningkatan nilai sosial dan ekonomi yang diusung dalam kegiatan ini memiliki tujuan yaitu: (1) menumbuhkan nilai sosial terhadap remaja serta anak usia dini, (2) meningkatkan pendapatan masyarakat melalui pelatihan berwirausaha. Metode pendekatan yang digunakan dalam kegiatan ini adalah: (1) Pendekatan religius (2) Pendekatan organisasi (3) Pendekatan kekerabatan (4) Pendekatan berdasarkan karakter masyarakat.
\end{abstract}

Kata kunci: Wirausaha, Pendidikan, Pemberdayaan

\section{PENDAHULUAN}

\section{Keadaan Geografis}

Secara umum keadaan Geografis

Desa Gunung malang merupakan daerah dataran tinggi yang terletak antara $6,39^{\circ}$ $14,7^{\circ}$ Lintang selatan dan $106,42^{\circ}-42,29^{\circ}$ Bujur timur, Dengan ketinggian $83 \mathrm{M}$ dari permukaan Laut dengan Luas 345.295 Ha. 1. Iklim

Desa Gunung malang beriklim Tropis dengan curah hujan rata - rata setahun tercatat $32 \mathrm{~mm}$ dari 0,08 hari hujan.

\section{Kondisi Keamanan dan Ketertiban}

Situasi Ketentraman dan Ketertiban diwilayah Desa Gunung malang cukup Kondusif.

\section{Kondisi Politik dan Pemerintah}

Tidak ada kerawanan sosial yang mengarah pada isu sara, situasi dan kondisi sosial politik diwilayah Desa Gunung Malang cukup kondusif, kejadian yang menonjol yang berkaitan dengan politik dapat diselesaikan dengan baik.

\section{Kondisi Masyarakat}

Pengabdian kepada masyarakat yang telah dilakukan mengambil tempat di Desa Gunung Malang, Kecamatan Tenjolaya, 
Kabupaten Bogor. Desa Gunung Malang merupakan sebuah desa mayoritas penduduknya terdiri dari kalangan masyarakat kelas menengah ke bawah dengan sumber penghasilan tidak menentu. Beberapa karakter masyarakat Gunung malang tepatnya di Kampung Pasir gaok RT 01/ RW 02 berdasarkan observasi dan wawancara yang telah dilakukan adalah sebagai berikut.

1. Hampir $70 \%$ masyarakatnya hanya berpendidikan SD, $15 \%$ SMP dan $15 \%$ SMA.

2. Jumlah remaja putus sekolah dan pengangguran cukup banyak. Fakta ini merupakan sebuah keprihatinan tersendiri karena minimnya keterampilan yang mereka miliki. Akibatnya, mereka sulit mendapatkan pekerjaan yang layak untuk menopang kehidupannya.

3. Dalam penelitian ini terdapat sejumlah fakta tentang kondisi terakhir masyarakat di Kampung Pasir Gaok. Di antaranya masih ditemukan perkawinan di bawah umur dan nikah di bawah tangan.

Dari data di atas, dapat disimpulkan bahwa masyarakat di Kampung Pasir gaok mempunyai dua masalah besar yakni :

1. Kemiskinan spiritual keagamaan.

2. kemiskinan ekonomi. Kemiskinan ini membuat mereka menjadi masyarakat kelas bawah yang tidak bisa berkembang menuju masyarakat mandiri. 


\section{METODE PELAKSANAAN}

\section{Tahapan Pelaksanaan}

Tahapan pelaksanaan untuk kegiatan ini sebagaimana terlihat pada bagan sebagai berikut:

Bagan Tahapan Pelaksanaan

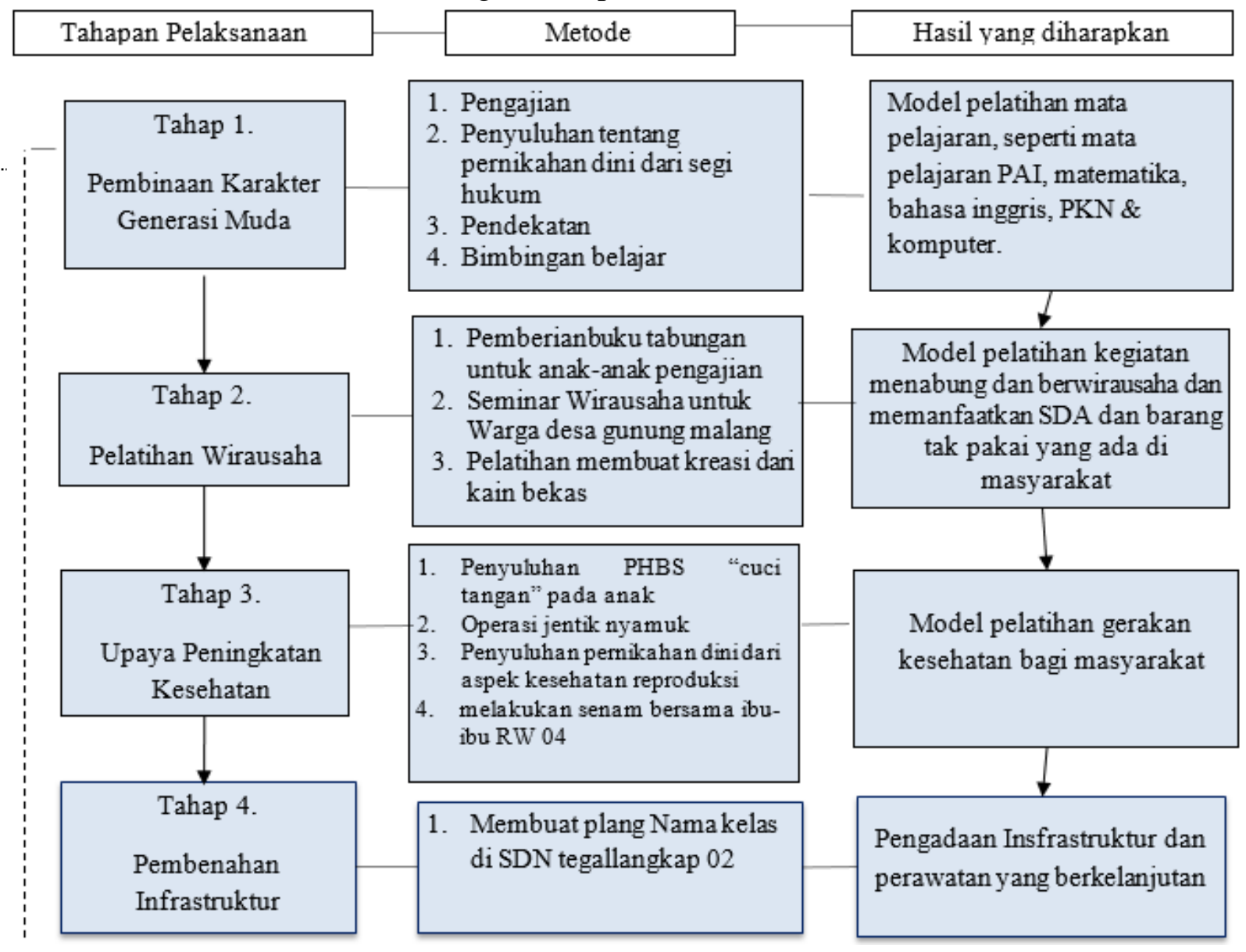

\section{Metode Pendekatan}

Pendekatan sosial dilakukan melalui tahapan-tahapan yang sistematis, meliputi tahapan:

\section{Pembukaan Hubungan}

Mahasiswa beserta DPL dapat mengadakan diskusi atau lokakarya dengan semua pihak strategis di masyarakat tentang rencana kerja.

2. Pemeliharaan Hubungan

Dalam pemeliharaan hubungan, komunikasi informal dapat memberikan hasil yang jauh lebih efektif.

\section{Pembinaan Hubungan}

Pembinaan hubungan Terkait dengan bagaimana menjaga agar hubungan tersebut tetap stabil saat $\mathrm{KKN}$ berlangsung.

\section{Mengakhiri Hubungan}

Pada tahap ini peserta KKN berpamitan dengan masyarakat, baik secara formal maupun personal.

\section{Partisipasi Masyarakat dalam \\ Pelaksanaan Program}

Partisipasi masyarakat yang dapat dilakukan dalam kegiatanini adalah sebagai berikut:

1) Menyediakan tempat tinggal bagi peserta KKN

2) Mempersiapkan tempat untuk pembinaan dan pelatihan. 
3) Pelaksanaan pengajian rutinan Warga (Bulanan / Mingguan ) bersama peserta KKN.

\section{Langkah Evaluasi}

Bentuk evaluasi yang dapat dirumuskan yaitu dinamai evaluasi proses; yang terkait dengan perencanaan, pelaksanaan dan monitoring kegiatan. Evaluasi proses akan dilakukan setiap hari oleh mahasiswa KKN 05.

Di antara evaluasi yang dilakukan terdiri dari:

\section{Bidang Pendidikan}

Pelaksanaan kegiatan Bidang Pendidikan dari masing-masing mahasiswa KKN 05 mendapatkan respon yang positif dari masyarakat sekitar. Namun, kendala di dalam pelaksanaan kegiatan dibidang pendidikan ini adalah waktu dari warganya serta kemauan belajar dari warga serta anak-anak dikampung pasir gaok yang masih kurang. Kendala lain adalah ada salah satu kampung yakni kampung rawa gabus yang berada jauh dari jalan raya, akses menuju kampung yang sulit terjangkau dan medan yang berbahaya menjadi salah satu kendala kampung tersebut sulit mendapatkan bantuan dari segi pendidikannya, tidak ada bangunan sekolah atau bahkan tenaga pengajarnya, maka kami mahasiswa KKN 05 yang harus terjun langsung ke sana, yang kami lakukan dalam 1 minggu 2 kali.

\section{Bidang Kesehatan}

Pelaksanaan kegiatan Bidang Kesehatan dari masing-masing mahasiswa KKN 05 mendapatkan respon yang positif dari masyarakat sekitar. akan hal tersebut. Mahasiswa memberikan penyuluhan Perilaku hidup sehat dan bersih yakni cuci tangan kepada anak SD kelas 1 A dan B. Dengan bekerja sama dengan bidang hukum mahasiswa (bidang kesehatan) membuat suatu penyuluhan tentang pernikahan dini dalam kajian kesehatan reproduksi. Mahasiswa melakukan kegiatan operasi jentik nyamuk kendalanya adalah masih ada warga yang belum menerima kedatangan mahasiswa.

\section{Bidang Ekonomi}

Pelaksanaan kegiatan Bidang Ekonomi dari masing-masing mahasiswa KKN 05 Universitas Ibn Khaldun mendapatkan respon yang positif dari masyarakat sekitar. Mahasiswa membuat suatu seminar kewirausahaan. Kendalanya masih banyak warga yang enggan datang karena kantor desa yang jauh dan tidak ada uang sakunya. Selain itu pembuatan kreasi dari kain bekas (membuat bros) dengan sasarannya adalah Remaja desa.

\section{Bidang Hukum}

Pelaksanaan kegiatan Bidang Hukum dari mahasiswa KKN 05 Universitas Ibn Khaldun mendapatkan respon yang positif. Banyaknya pernikahan dini di desa gunung malang membuat mahasiswa meresponnya dengan membuat penyuluhan pernikahan dini dalam kajian hukum dan kesehatan. Dengan berkonsep seperti kajian sasaran kegiatan penyuluhan kali ini adalah ibu rumah tangga dan anak-anak perempuan usia 12 tahun ke atas. Dengan kegiatan ini mahasiswa mengharapkan agar setiap ibu mampu memahami regulasi-regulasi nasional terkait dengan larangan pernikahan dini bagi anak dibawah umur.

\section{Bidang Agama}

Pelaksanaan kegiatan Bidang Agama dari mahasiswa KKN 05 Universitas Ibn Khaldun mendapatkan respon yang positif dari masyarakat sekitar. Mengajar mengaji di rumah ustad umar dan ustajah yama adalah bentuk kepedulian mahasiswa untuk membantu ustad dan ustajah. Banyaknya anak-anak yang mengaji membuat jam pulang mengaji yang tadinya jam 17.00 menjadi 17.30, dengan adanya mahasiswa 
ustajah menjadi terbantu, dan ustad umar dengan kesibukannya sering tidak melaksanakan pengajian, dengan adanya mahasiswa ustad merasa terbantu juga, selain itu perbaikan mahraj huruf serta memperbaikan bacaan Qur'an anak-anak juga menjadi target utama mahasiswa. Selain membantu pengajian anak-anak mahasiswa juga membuka bimbingan belajar bahasa arab di posko. Dengan bergabung dengan bidang pendidikan mahasiswa membuat kosa kata pada ruangan kelas dalam 3 bahasa yakni Arab, Inggris dan Indonesia yang dipasang ke semua ruangan yang ada di SDN Tegallangkap 02 Tenjolaya. Diakhir kkn mahasiswa membuat perpisahan dan santunan anak yatim untuk anak-anak yatim dan piatu di kawasan RW 04.

\section{Bidang Teknik}

Pelaksanaan kegiatan Bidang Teknik dari mahasiswa KKN 05 Universitas Ibn

\section{HASIL DAN PEMBAHASAN}

Pelaksanaan program kerja selama 30 hari diantaranya :

\section{Bidang Pendidikan}

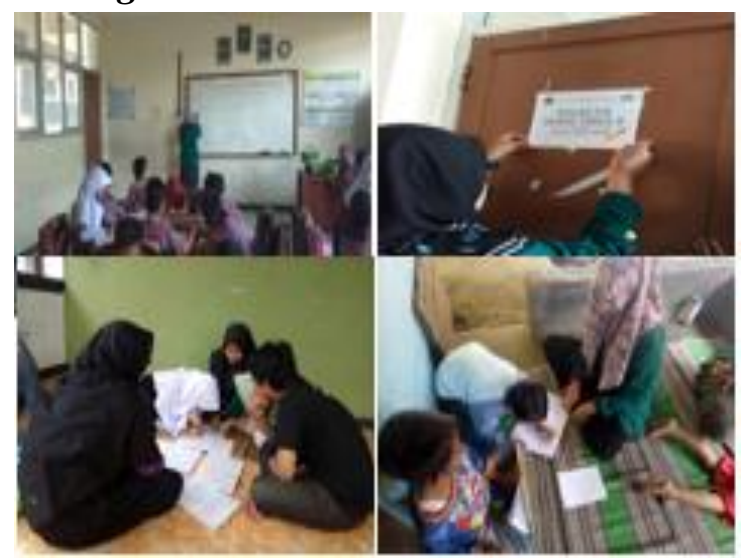

1. Mengajar di SDN Tegallangkap 02 dan kampung Rawa Gabus

2. Bimbel Matematika, Bahasa Inggris, Bahasa Arab di Posko 05

3. Pembuatan kosa kata pada setiap ruangan di SDN Tegallangkap 02 (Bahasa Indonesia - Inggris - Arab)
Khaldun mendapatkan respon yang positif dari masyarakat sekitar. Informasi tentang desa merupakan hal yang sangat penting, untuk desa gunung malang informasi yang ada belum terlalu lengkap, mahasiswa melakukan pembahan informasi tentang desa gunung malang di wikipedia agar lebih lengkap lagi serta membuat penambahan disalah satu jalan yang ada didesa gunung malang malang kampung pasir gaok karena sebelumnya ada warga yang meminta bantuan kepada mahasiswa. Teknologi adalah hal terpenting dizaman modern saat ini, mahasiswa dengan kepeduliannya membuat kegiatan bimbingan belajar komputer untuk kalangan anak-anak sampai remaja. Mahasiswa juga membuat penyuluhan tentang hemat energi rumah tangga dengan sasaran nya adalah ibu-ibu rumah tangga.

\section{Bidang Hukum}

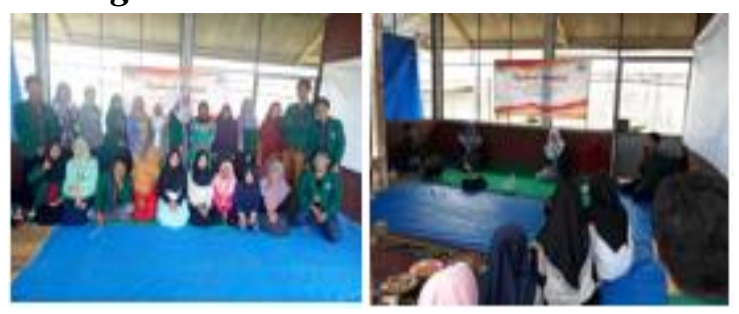

Penyuluhan tentang Pernikahan Dini dalam Perspektif Hukum Nasional

\section{Bidang Ekonomi}

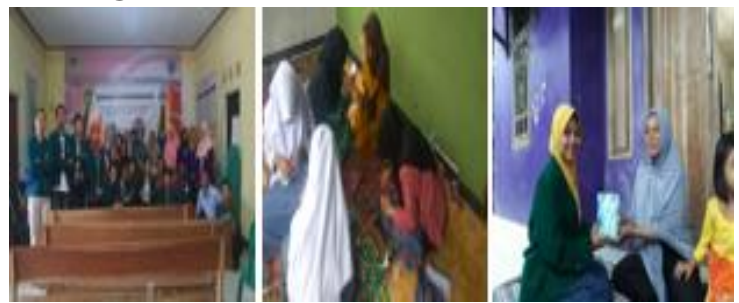

1. Seminar tentang Kewirausahaan

2. Pemberian buku tabungan

3. Pembuatan bros dari kain bekas 
Bidang Teknik

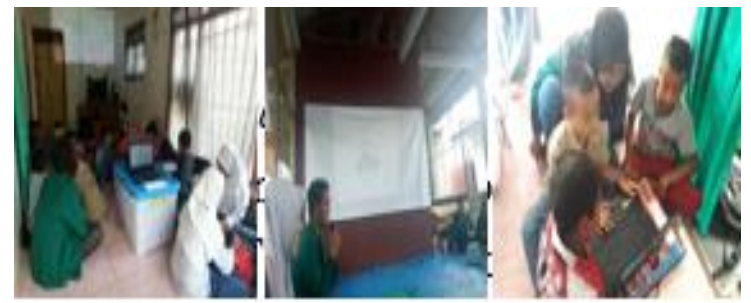

1. Penambahan informasi tentang desa Gunung Malang di Wikipedia

2. Bimbingan belajar computer

3. Penyuluhan tentang hemat energy rumah tangga

4. Penambahan lokasi desa Gunung Malang (gang Dewi) di Google Maps

\section{Bidang Kesehatan}

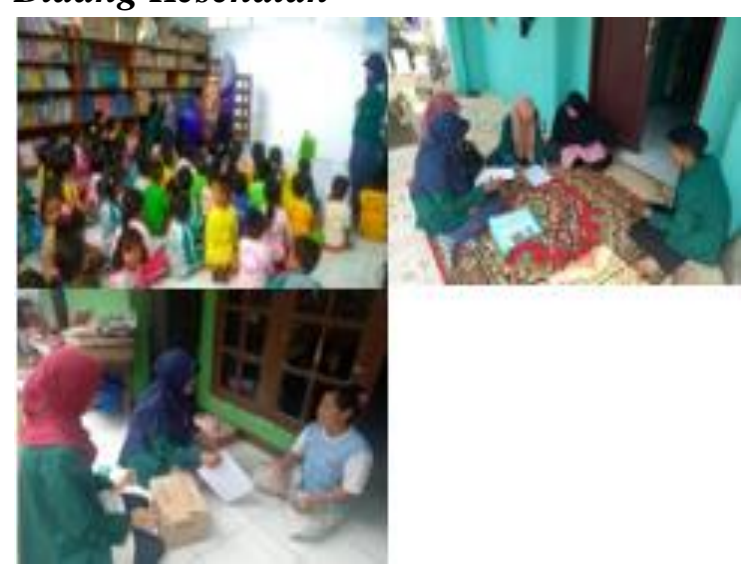

\section{KESIMPULAN}

Berikut beberapa kesimpulan yang dapat kami jabarkan selama program KKN yang berlangsung kurang lebih selama 30 hari di Desa Gunung Malang Kecamatan Tenjolaya :

1. Terealisasinya program pengabdian kepada masyarakat yang dilakukan oleh mahasiswa dalam rangka mewujudkan program Universitas Ibn Khaldun Bogor sesuai dengan Visi dan Misi Universitas Ibn KhaldunBogor.

2. Terbentuknya karakter Kepemimpinan serta kemandirian para mahasiswa dan
1. Penyuluhan PHBS program CTPS (Cuci Tangan Pakai Sabun)

2. Opera jentik nyamuk (pembagian ABATE secara gratis)

3. Penyuluhan tentang Pernikahan Dini dari segi Kesehatan Reproduksi

\section{Bidang Agama}

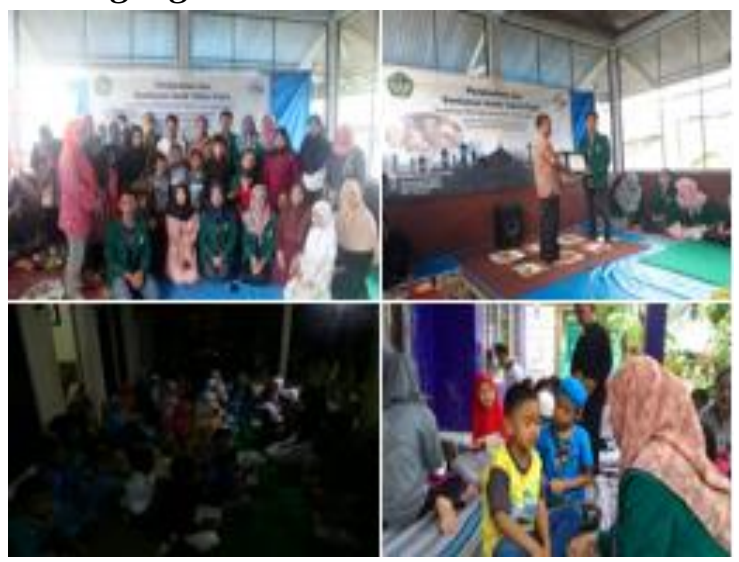

1. Mengajar ngaji di rumah ustad Umar dan ustazah Yama

2. Bimbingan belajar bahasa Arab

3. Pembuatan kosa kata pada setiap ruangan di SDN Tegallangkap 02 (Bahasa Arab-Inggris - Indonesia)

4. Santunan anak yatim

mahasiswi yang mengikuti program KKN ini.

3. Terbentuknya program kerjasama langsung antara mahasiswa dan masyarakat yang bisa saling bersinergi dan saling menguntungkan.

4. Meningkatkan kepedulian dan rasa empati mahasiswa kepada permasalahan masyarakat, sehingga terjadinya perubahan perilaku mahasiswa kepada masyarakat 


\section{REKOMENDASI}

Berikut beberapa Saran dan Rekomendasi yang dapat kami jabarkan selama program KKN yang berlangsung kurang lebih selama 30 hari di Desa Gunung Malang Kecamatan Tenjolaya :

1. Pemberian dukungan moral ataupun moril yang lebih dari aparat Desa setempat.

\section{REFERENSI}

Suhandi, Agraha. 1993. Pola Hidup Masyarakat Indonesia. Bandung: Fakultas Sastra Universitas Padjajaran.

Dewi, Yuni Retna. 2006. Teknik Komunikasi Pada Proses Pendekatan Masyarakat (Makalah). Jakarta: LPM Universitas Trisakti.

Daryanto, 2014. Perubahan pendidikan
2. Saling bekerjasama para pihak yang terkait, baik dari Dinas Kepemerintahan, pihak swasta, dan maupun kesadaran para masyarakat sendiri

dalam dalam masyarakat social budaya, Jakarta : Satu nusa.

https://books.google.co.id/books/about/Sos iologi_Menyelami_Fenomena_Sosial di_M.html?hl=id\&id=1ayp70vvhX MC\&redir_esc $=y$

https://id.wikipedia.org/wiki/Gunung_Mal ang,_Tenjolaya,_Bogor 